\title{
FoxO3a depletion accelerates cutaneous wound healing by regulating epithelial-mesenchymal transition through $\beta$-catenin activation
}

\author{
TING LIU, JING-ZHUO HUANG, ZE-YUAN LEI, RONG-SHUAI YAN and DONG-LI FAN \\ Department of Plastic and Cosmetic Surgery, The Second Affiliated Xinqiao Hospital \\ of Army Medical University, Chongqing 400037, P.R. China
}

Received January 25, 2019; Accepted November 18, 2019

DOI: $10.3892 / \mathrm{mmr} .2020 .10912$

\begin{abstract}
The hysteresis of keratinocyte (KC) re-epithelialization is an important factor resulting in chronic wounds; however, the molecular mechanisms involved in this cellular response remain yet to be completely elucidated. The present study demonstrated the function of transcription factor Forkhead box $\mathrm{O} 3 \mathrm{a}$ (FoxO3a) in $\mathrm{KC}$ growth and migration functional effects, resulting in restrained $\mathrm{KC}$ re-epithelialization during wound healing. In chronic wound tissue samples, the expression of FoxO3a was significantly increased when compared with the acute wound healing group $(\mathrm{P}<0.01)$. Overexpressing FoxO3a significantly inhibited, whereas silencing endogenous FoxO3a enhanced, the growth and migration of HaCaT cells in vitro. Further investigation revealed that FoxO3a negatively regulated matrix metalloproteinases 1 and 9, and increased the expression of tissue inhibitor of metalloproteinase 1. In addition, the upregulation of FoxO3a retarded, whereas the downregulation of FoxO3a accelerated, transforming growth factor- $\beta 1$-induced epithelial-mesenchymal transition in $\mathrm{HaCaT}$ cells. Mechanistically, the overexpression of FoxO3a inactivated $\beta$-catenin signaling and markedly reduced the levels of nuclear $\beta$-catenin. These results reveal a novel mechanism of FoxO3a in regulating $\mathrm{KC}$ re-epithelialization, and provide novel targets for the prevention and treatment of chronic wounds.
\end{abstract}

\section{Introduction}

Human skin is the largest organ of the body with a number of important physiological functions including sensation,

Correspondence to: Dr Dong-Li Fan, Department of Plastic and Cosmetic Surgery, The Second Affiliated Xinqiao Hospital of Army Medical University, 183 Xinqiao Main Street, Shapingba, Chongqing 400037, P.R. China

E-mail: fdltmmu@sina.com

Key words: Forkhead box O3a, epithelial-mesenchymal transition, keratinocytes, re-epithelialization, chronic wounds absorption, secretion, excretion and protection, and participates in various metabolic processes in organisms, maintaining the stability of the internal environment $(1,2)$. Extensive damage to skin integrity caused by trauma or disease may result in severe disability or even mortality (3); therefore, identifying targets for the prevention and treatment of chronic non-healing wounds is a major scientific problem that requires further investigation.

Cutaneous wound repair is a multi-step process involving inflammation, re-epithelialization and tissue remodeling. The re-epithelialization of keratinocytes (KCs) is a crucial component of wound repair, remodeling the epidermal barrier through the migration, proliferation and differentiation of epithelial cells near the edge of the wound (4). Defects or delays in re-epithelialization are essential in the complex or slow healing of wounds (5). The results of a chronic wound biopsy have revealed that the epithelial cells in the re-epithelialization stage are active and overproliferated, but surprisingly had no apparent occurrence in cell migration (6). However, the persistent re-epithelialization of the wound easily results in abnormal healing, resulting in scar hyperplasia, secondary infection or deformity, seriously affecting the health of patients (7). Consequently, it is important to investigate the molecular mechanism of the $\mathrm{KC}$ re-epithelialization process, and identify a fast and effective way to regulate this process and to achieve the purpose of preventing and treating refractory wounds in the clinic.

Forkhead box O3a (FoxO3a), a FoxO protein member of the Forkhead transcription factor family, located on human chromosome 6q21, is widely distributed in the human body (8). Its transcriptional activity is mainly regulated by post-translational modifications including phosphorylation, acetylation, ubiquitination and methylation (9). Previous studies have demonstrated that FoxO3a may integrate different signals to participate in the regulation of internal environment stability and serve an integral function in embryonic development, follicular maturation, glucose homeostasis, cell proliferation and apoptosis and DNA damage repair (10-12). In addition, FoxO3a functions as an anti-oncogene by promoting apoptosis, inhibiting proliferation, controlling the differentiation of tumor cells and suppressing angiogenesis through interactions with other transcription factors in the process 
of tumorigenesis (13). Upregulation of FoxO3a expression substantially inhibits the invasion and migration abilities of colonic carcinoma cells (14). In prostate cancer cells, FoxO3a negatively regulates the epithelial-mesenchymal transition (EMT) process by mediating the classical Wnt signaling pathway (15). In the field of wound healing, one previous study has revealed that a notable decrease in FoxO3a expression, in wounded human and mouse skin subsequent to an injury, was observed (16) and FoxO3a knockout mice have been reported to have a substantially accelerated rate of wound healing (17). However, whether FoxO3a serves a similar regulatory function in KC EMT in wound re-epithelialization has not been reported.

The present study investigated the expression of FoxO3a in human chronic and acute wound tissues, and the mechanism of FoxO3a in wound re-epithelialization at a molecular level. The results may provide a novel entry point for investigating the mechanism of chronic refractory wound healing.

\section{Materials and methods}

Patients and clinical specimens. A total of 20 human chronic (at least 4 weeks after injury) and acute wound (within one week after injury) specimens were collected according to the protocol that was ethically approved by the Research Ethics Committee of The Second Affiliated Xinqiao Hospital of Army Medical University (Chongqing, China) between January 2016 and October 2016, and written informed consent was obtained from each patient prior to surgery. The patients included 8 males and 12 females, with a median age of 40 years (range, 8-72 years). All specimens were immediately snap-frozen in liquid nitrogen and maintained at $-80^{\circ} \mathrm{C}$ until subsequent use.

Immunohistochemistry staining. For immunohistochemical analysis of FoxO3a expression, the tissues were fixed in $10 \%$ formalin for $24 \mathrm{~h}$ at room temperature and embedded in paraffin. 4- $\mu \mathrm{m}$ thick consecutive sections were cut using microtome, deparaffinized with xylol and rehydrated with graded ethanol solutions (100, 95, 80 and 50\%). Endogenous peroxidase activity was blocked using $3 \%$ hydrogen peroxide for $10 \mathrm{~min}$ at room temperature. The sections were then subjected to antigen retrieval for $5 \mathrm{~min}$ by heating at $100^{\circ} \mathrm{C}$ in $10 \mathrm{mM}$ of citric acid, $\mathrm{pH}$ 6.0. Subsequent to blocking non-specific binding with normal goat serum (1:20; cat. no. C0265; Beyotime Institute of Biotechnology) at room temperature for $20 \mathrm{~min}$, the sections were then incubated with anti-FoxO3a primary antibody (1:100; cat. no. ab12162; Abcam) at $4^{\circ} \mathrm{C}$ overnight. The next day, following three washes with phosphate buffered saline (PBS), sections were incubated with a goat anti-rabbit horseradish peroxidase (HRP)-conjugated secondary antibody (1:100; cat. no. A0208; Beyotime Institute of Biotechnology) for $30 \mathrm{~min}$ at room temperature. Hematoxylin was used as the nuclear counterstain for $3 \mathrm{~min}$ at room temperature and 3,3'-diaminobenzidine as the chromogen. Finally, sections were observed under a light microscope (magnification, x200; Nikon Corporation).

Cell culture. The human $\mathrm{KC} \mathrm{HaCaT}$ cell line was purchased from the Type Culture Collection of the Chinese Academy of Sciences and cultured in high glucose Dulbecco's modified Eagle's medium (DMEM; Hyclone; GE Healthcare Life Sciences) supplemented with $10 \%$ fetal bovine serum (FBS; Hyclone; GE Healthcare Life Sciences), $100 \mathrm{U} / \mathrm{ml}$ penicillin and $100 \mu \mathrm{g} / \mathrm{ml}$ streptomycin (Sigma-Aldrich; Merck $\mathrm{KGaA}$ ) in an incubator with $5 \% \mathrm{CO}_{2}$ at $37^{\circ} \mathrm{C}$. For stimulation experiments, $\mathrm{HaCaT}$ cells were seeded in 6 -well plates at a density of $2 \times 10^{5} /$ well. Before stimulation with recombinant transforming growth factor- $\beta 1$ (TGF- $\beta 1 ; 10 \mathrm{ng} / \mathrm{ml}$; cat. no. P01137; R\&D Systems, Inc.), the cells were incubated with serum-free DMEM for $12 \mathrm{~h}$ at $37^{\circ} \mathrm{C}$. Subsequent to stimulation for $48 \mathrm{~h}$ at $37^{\circ} \mathrm{C}$, western blot analysis was performed to analyze EMT-related gene and FoxO3a expression.

Regulation of FoxO3a expression by Lentivirus 3xflag-FoxO3a (lenti-3xflag-FoxO3a) and FoxO3a small interfering (si)-RNA. The lenti-3xflag-FoxO3a and control vector lenti-3xflag were provided by Shanghai GenePharma Co., Ltd., and used to establish the $\mathrm{HaCaT}$ cells with FoxO3a overexpression. HaCaT cells were seeded in 6 -well plates at a density of $2 \times 10^{5} /$ well and infected with the constructed lentiviruses (flag-FoxO3a), at a multiplicity of infection of 10 , with $8 \mu \mathrm{g} / \mathrm{ml}$ polybrene. The siRNA sequences for FoxO3a and the negative control (NC) were 5'-GCUGUCUCCAUGGACAAUATT-3' and 5'-UUCUCCGAACGUGUCACGUTT-3', respectively. siRNA (80 nM) was transfected into HaCaT cells using Lipofectamine $^{\mathrm{TM}}$ RNAiMAX (Invitrogen; Thermo Fisher Scientific, Inc.) according to the manufacturer's protocol. Subsequent to infection or transfection, cells were incubated for $48 \mathrm{~h}$ at $37^{\circ} \mathrm{C}$, then they were harvested and reverse transcription-quantitative (RT-q)PCR and western blot analysis were performed to analyze FoxO3a expression.

Wound scratch assay. A scratch wound healing assay was performed to evaluate the migration of cells. Following infection or transfection, the cells $\left(1 \times 10^{6} /\right.$ well) were collected and seeded in 6-well plates. When the cells merged into a monolayer, a sterile $200 \mu \mathrm{l}$ pipette tip was used to create a straight scratch on the surface of the cell layer and the cells were cultured in a serum-free DMEM. Following $24 \mathrm{~h}$ of incubation at $37^{\circ} \mathrm{C}$, the cells were washed with PBS twice, the wound healing areas were imaged under an inverted microscope (magnification, x200) and the wound widths were analyzed using ImageJ 1.48 software (National Institutes of Health).

Cell viability assay. A Cell Counting Kit (CCK)-8 cell viability assay (Dojindo Molecular Technologies, Inc.) was used to verify that FoxO3a caused a change in the growth of $\mathrm{HaCaT}$ cells according to the manufacturer's protocol. Briefly, $\mathrm{HaCaT}$ cells were plated into 96 -well plates at a density of $1 \times 10^{3}$ cells/well and cultured in a humidified $37^{\circ} \mathrm{C}, 5 \% \mathrm{CO}_{2}$ incubator for 2 days. Then, $10 \mu \mathrm{l}$ CCK- 8 reagent was added to each well, and the absorbance was detected at $450 \mathrm{~nm}$ using a microplate reader.

$R T-q P C R$. The total RNA of human wound (chronic and acute) tissues and HaCaT cells was extracted using TRIzol ${ }^{\circledR}$ regent (Invitrogen; Thermo Fisher Scientific, Inc.) according to the manufacturer's protocol, and $1 \mu \mathrm{g}$ RNA was reverse transcribed (reaction conditions: $70^{\circ} \mathrm{C}$ for $10 \mathrm{~min}, 42^{\circ} \mathrm{C}$ for $60 \mathrm{~min}$ and $70^{\circ} \mathrm{C}$ for $10 \mathrm{~min}$ ) into cDNA using a Reverse Transcriptase 
kit (Promega Corporation). GAPDH served as an internal control. The following primers were used: FoxO3a forward, 5'-AAGCCAGCTACCTTCTCTTCCA-3' and reverse, 5'-GTG GCAAGTCAGTCCGAACTGA-3'; and GAPDH forward, 5'-CGGAGTCAACGGATTTGGTCGTAT-3' and reverse, 5'-AGCCTTCTCCATGGTGGTGAAGAC-3'. The target gene expression was examined on a CFX96 Touch $^{\mathrm{TM}}$ Real-Time PCR Detection System (Bio-Rad Laboratories, Inc.) and qPCR was performed using the SYBR ${ }^{\circledR}$ Premix Ex Taq ${ }^{\mathrm{TM}}$ II (Takara Biotechnology Co., Ltd.). The thermocycling reaction conditions were as follows: $93^{\circ} \mathrm{C}$ for $2 \mathrm{~min}$, followed by 40 cycles of $93^{\circ} \mathrm{C}$ for $1 \mathrm{~min}, 55^{\circ} \mathrm{C}$ for $30 \mathrm{sec}$ and $72^{\circ} \mathrm{C}$ for $1 \mathrm{~min}$. Finally, gene expression data were evaluated according to the $2^{-\Delta \Delta \mathrm{Cq}}$ method (18).

Western blot analysis. Total protein from human wound (chronic and acute) tissues and $\mathrm{HaCaT}$ cells was extracted using RIPA Lysis reagent (cat. no. P0013K; Beyotime Institute of Biotechnology) and quantified via the bicinchoninic acid assay method. The isolation of cytoplasmic and nuclear proteins was performed according to methods published previously (19). Western blot analysis was performed as previously described (20). Briefly, total protein (40 $\mu \mathrm{g} / \mathrm{lane}$ ) was separated by 10\% SDS-PAGE (cat. no. P0690; Beyotime Institute of Biotechnology), transferred to nitrocellulose membranes (cat. no. FFP33; Beyotime Institute of Biotechnology). The membranes were blocked with $5 \%$ skim milk for $1 \mathrm{~h}$ at room temperature and then probed overnight using primary antibodies at $4^{\circ} \mathrm{C}$, including anti-FoxO3a (1:500; cat. no. ab12162), anti- $\beta$-catenin (1:1,000; cat. no. ab2365), anti-Histone H3 (nuclear marker; 1:2,000; cat. no. ab1791; all Abcam), anti-matrix metalloproteinase 1 (MMP-1; 1:1,000; cat. no. 54376), anti-MMP-9 (1:1,000; cat. no. 13667), anti-tissue inhibitor of metalloproteinase 1 (TIMP-1; 1:1,000; cat. no. 8946), anti-E-cadherin (1:500; cat. no. 3195), anti-N-cadherin (1:500; cat. no. 13116; all Cell Signaling Technology, Inc.), anti-vimentin (1:1,000; cat. no. AF1975) and anti-GAPDH (1:3000; cat. no. AF1186; both Beyotime Institute of Biotechnology). Subsequently, the membranes were incubated for $1 \mathrm{~h}$ at $37^{\circ} \mathrm{C}$ with a goat anti-rabbit HRP-conjugated secondary antibody (1:2,000; cat. no. 7074; Cell Signaling Technology, Inc.). Finally, proteins were visualized using an enhanced chemiluminescent detection reagent (Beyotime Institute of Biotechnology) and the blots were analyzed using ImageJ 1.48 software (National Institutes of Health).

Immunofluorescence. For immunofluorescence, HaCaT cells $\left(2 \times 10^{5}\right)$ were plated into a confocal small dish, washed twice with PBS, fixed with $4 \%$ paraformaldehyde for $10 \mathrm{~min}$ at room temperature, permeabilized with $0.5 \%$ Triton-X-100/PBS for $5 \mathrm{~min}$ and blocked with $1 \% \mathrm{BSA}$ for $1 \mathrm{~h}$ at room temperature. The cells were then washed again with PBS twice, and stained with the appropriate primary antibodies: Anti-E-cadherin (1:200; cat. no. 3195; Cell Signaling Technology, Inc.); and anti-vimentin (1:100; cat. no. AF1975; Beyotime Institute of Biotechnology) overnight at $4^{\circ} \mathrm{C}$. Followed by incubation with the appropriate secondary antibodies: Alexa Fluor ${ }^{\circledR}$ 488-conjugated goat anti-rabbit IgG (1:250; cat. no. ab150077; Abcam); and Alexa Fluor 555-Labeled Donkey anti-Rabbit IgG (1:250; cat. no. P0179; Beyotime Institute of Biotechnology) for $1 \mathrm{~h}$ at $37^{\circ} \mathrm{C}$, respectively. Subsequent to washing twice with PBS, Hoechst staining was performed at room temperature for $3 \mathrm{~min}$ and the fluorescence was visualized with a confocal microscope (magnification, $\mathrm{x} 400$ ).

Statistical analysis. All experimental data are presented as the mean \pm SD and were analyzed using GraphPad Prism 7 software (GraphPad Software, Inc.). Statistical differences were obtained via paired or unpaired Student's t-test between two groups, and a one-way ANOVA followed by Tukey's post hoc test amongst multiple groups. $\mathrm{P}<0.05$ was considered to indicate a statistically significant difference, and each experiment was conducted in triplicate.

\section{Results}

Expression and distribution of FoxO3a in human chronic and acute wound tissues. In the initial set of experiments, in order to characterize the FoxO3a expression pattern in human chronic and acute wound tissues, immunohistochemistry was performed on sections of cutaneous samples collected post-wounding. As presented in Fig. 1A, the expression of FoxO3a was substantially upregulated in the chronic wounds compared with the acute wound tissues. Consistent with these results, the present study also analyzed the expression levels of FoxO3a using RT-qPCR and western blot analysis, and the results revealed that FoxO3a mRNA expression levels were significantly increased in the chronic wounds compared with the acute wound tissues $(\mathrm{P}<0.01)$, as was the protein expression (Fig. 1B and C).

Silencing FoxO3a facilitates, while its overexpression inhibits, the growth and migration of HaCaT cells in vitro. To further clarify whether FoxO3a is associated with $\mathrm{KC}$ re-epithelialization following injury, the present study used a FoxO3a overexpressing lentivirus vector and FoxO3a siRNAs to perform FoxO3a gain- and loss-of-function studies in $\mathrm{HaCaT}$ cells. The efficiency of FoxO3a expression was then detected using RT-qPCR and western blot analysis (Fig. 2A and B). In addition, CCK-8 and wound scratch assays were performed to investigate the function of FoxO3a in the growth and migration capacity of $\mathrm{HaCaT}$ cells. As presented in Fig. 2C and E, FoxO3a silencing in $\mathrm{HaCaT}$ cells significantly enhanced cell growth compared with NC cells $(\mathrm{P}<0.05)$, and the cell migration capacity was increased. Conversely, a significantly lower growth rate and inhibited motility capacity were observed in the Lenti-Flag-FoxO3a group compared with the control $(\mathrm{P}<0.05$; Fig. 2D and F). These results suggest that the depletion of FoxO3a results in the notable enhancement of the growth and migration abilities of KCs in the re-epithelialization process.

FoxO3a depletion promotes MMP-1 and MMP-9, and inhibits TIMP-1, expression. Wound repair is a highly complex process that requires the participation of numerous different extracellular matrix (ECM) components, cells and soluble media (21). $\mathrm{KCs}$ promote cell migration, re-epithelialization and neovascularization by secreting MMPs during the proliferative phase of wound healing. A previous study demonstrated that MMP-1 and MMP-9 are significantly increased in chronic wound healing, while TIMP-1 levels are significantly decreased (22). 
A

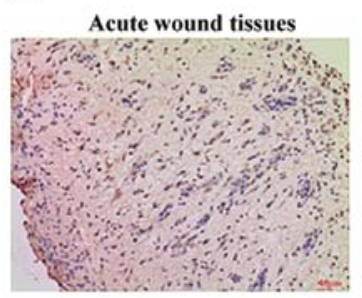

Chronic wound tissues

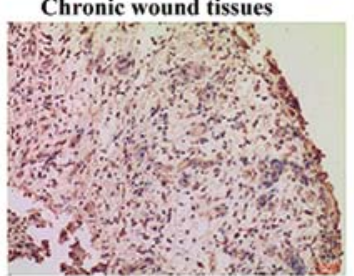

B

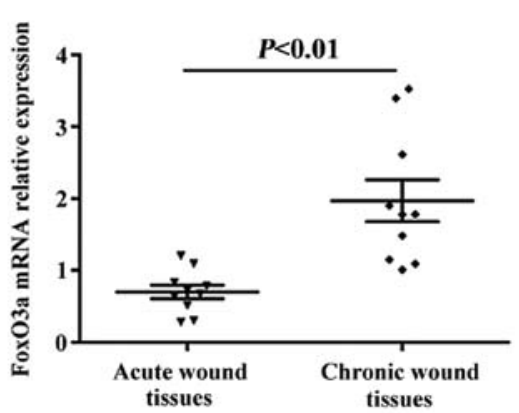

C

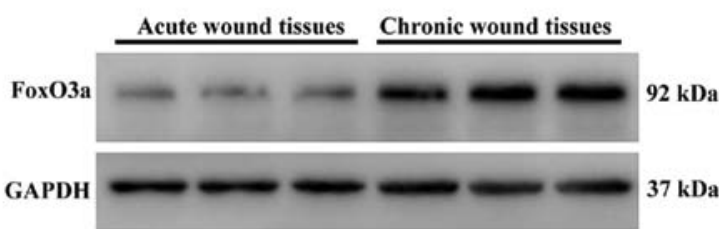

Figure 1. Higher expression levels of FoxO3a in human chronic wounds. (A) Representative images of immunostained human acute and chronic wound tissues exhibiting FoxO3a protein expression (magnification, x40). (B) mRNA expression levels of FoxO3a in 10 pairs of chronic and acute wound tissues were detected using a reverse transcription-quantitative polymerase chain reaction; $\mathrm{P}<0.01$. (C) Representative western blot analysis results of three randomly selected cases of chronic and acute wound tissues are presented. FoxO3a, Forkhead box O3a.
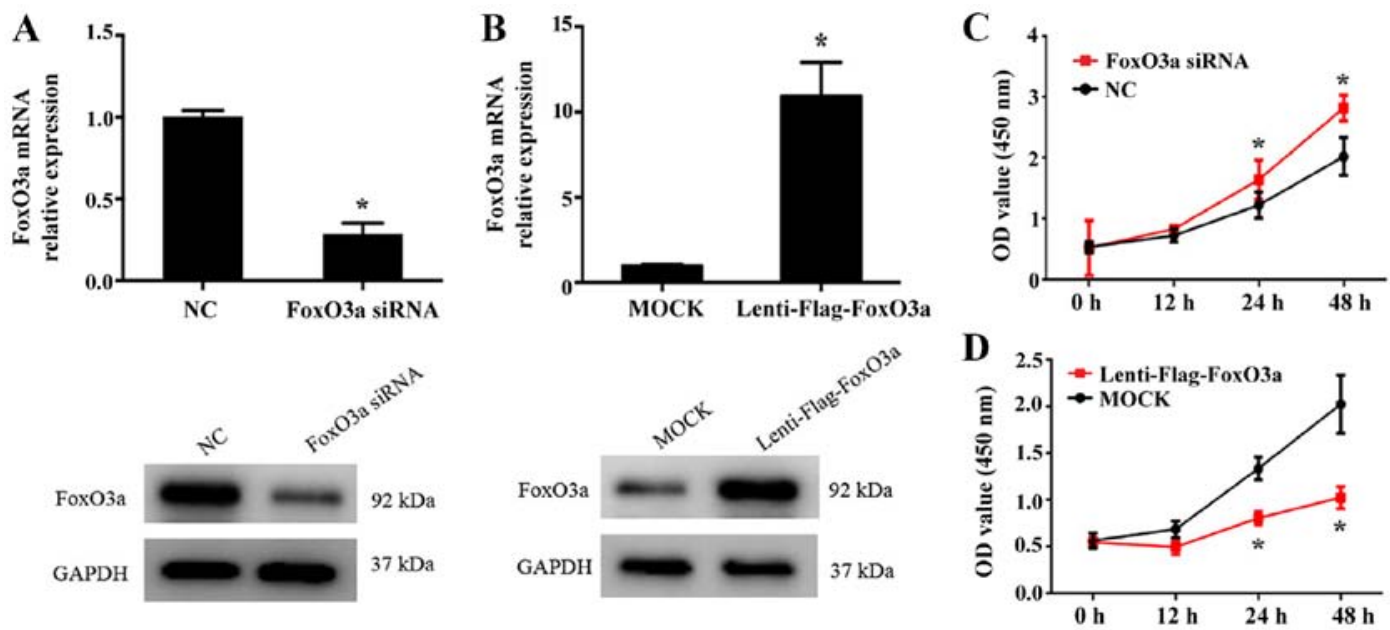

$\mathbf{E}$

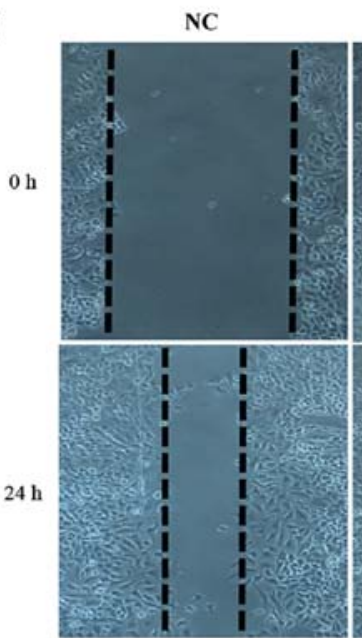

FoxO3a siRNA

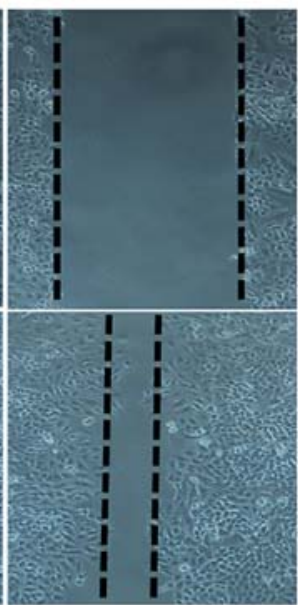

F

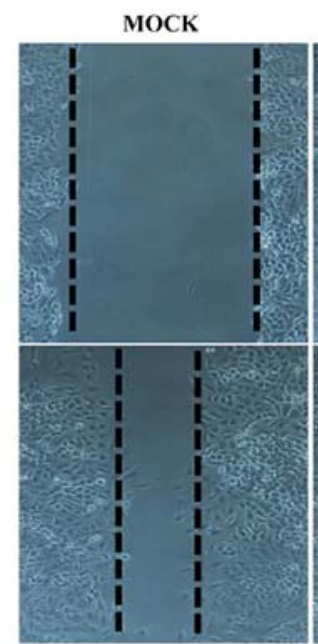

Lenti-Flag-FoxO3a

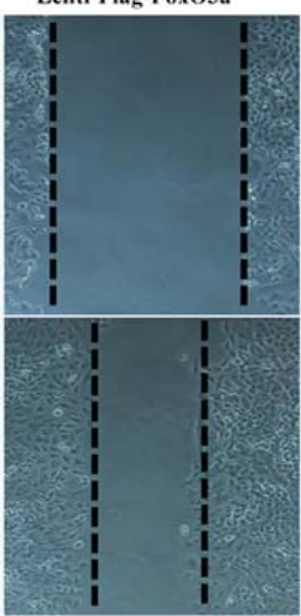

Figure 2. Effect of FoxO3a on $\mathrm{HaCaT}$ cell growth and migration in vitro. Results of reverse transcription-quantitative polymerase chain reaction (upper panel) and western blot analysis (lower panel) demonstrated (A) FoxO3a silencing (HaCaT cells transfected with FoxO3a-siRNA) and (B) overexpression (HaCaT

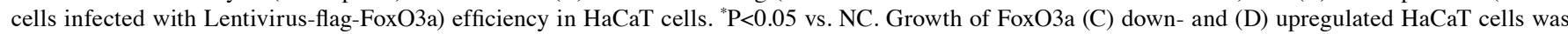
observed by Cell Counting Kit- 8 assays at the indicated time points. "P<0.05 vs. MOCK/NC groups. Representative images from the wound scratch assay once $\mathrm{HaCaT}$ cells were treated with (E) FoxO3a siRNA or (F) Lentivirus-flag-FoxO3a (magnification, x200). FoxO3a, Forkhead box O3a; NC, negative control; siRNA, small interfering RNA; OD, optical density. 

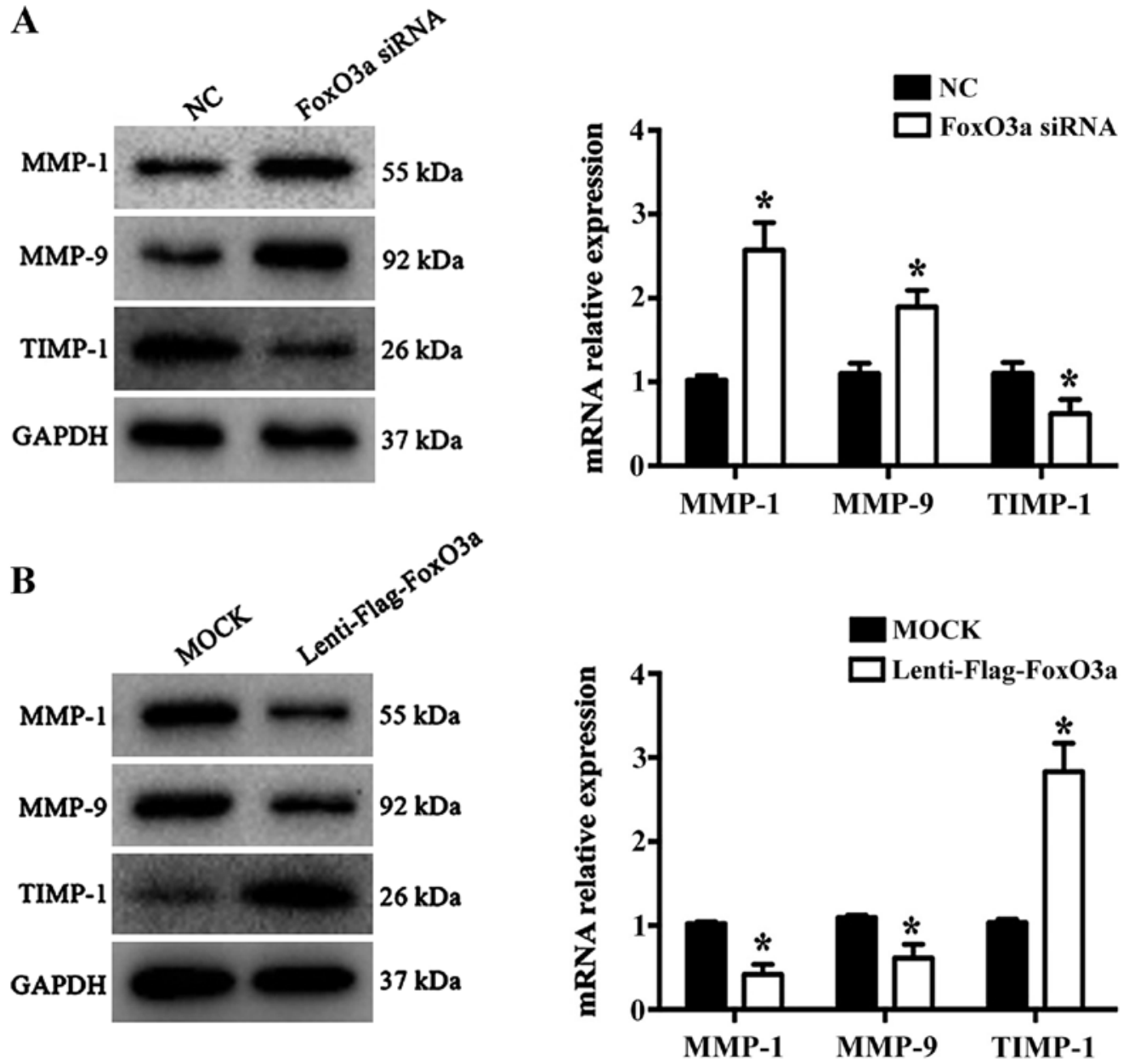

Figure 3. FoxO3a regulates the expression of MMPs/TIMPs proteins. (A) Silencing of FoxO3a expression increased MMP-1 and MMP-9 expression, and decreased TIMP-1 levels in HaCaT cells. " $\mathrm{P}<0.05$ vs. NC. (B) Overexpression of FoxO3a downregulated MMP-1 and MMP-9 levels and upregulated TIMP-1 expression in $\mathrm{HaCaT}$ cells. "P<0.05 vs. MOCK. FoxO3a, Forkhead box O3a; MMP, matrix metalloproteinase; TIMP-1, tissue inhibitor of metalloproteinase 1; $\mathrm{NC}$, negative control; siRNA, small interfering RNA.

In the present study, the results revealed that the mRNA levels and protein expression of MMP-1 and MMP-9 were significantly increased $(\mathrm{P}<0.05)$, while TIMP-1 was significantly decreased in the FoxO3a siRNA group compared with the NC group ( $\mathrm{P}<0.05$; Fig. 3A). Conversely, the opposite results were observed in FoxO3a-enhanced HaCaT cells (Fig. 3B). These data suggested that FoxO3a may regulate the expression of MMP-1, MMP9 and TIMP-1 to control ECM degradation in HaCaT cell migration.

Construction of the EMT model of HaCaT cells and FoxO3a expression downregulation. In the early stage of wound healing, KCs acquire the characteristics of interstitial cells to enhance the motor ability and then migrate to the reconstructed area under cytokine action (23). At the molecular level, the expression of interstitial cell markers including $\mathrm{N}$-cadherin and vimentin were increased, and the epithelial cell marker E-cadherin protein was decreased (24). In the present study, $10 \mathrm{ng} / \mathrm{ml}$ TGF- $\beta 1$ was added to the HaCaT cells, and the results revealed that the expression of E-cadherin was substantially decreased, whereas the expression of vimentin and $\mathrm{N}$-cadherin protein were increased (Fig. 4A); consistent results were observed in $\mathrm{HaCaT}$ cells upon FoxO3a downregulation
(Fig. 4B). Furthermore, the expression of FoxO3a protein in the TGF- $\beta 1$ group exhibited a decreasing trend compared with the control group. It was indicated that the EMT model was successfully established, and FoxO3a was regarded as a negative regulatory factor that participated in the TGF- $\beta 1$ induced-EMT process of HaCaT cells.

Overexpression of FoxO3a suppresses TGF- $\beta 1$ induced-EMT and $\beta$-catenin activation. To further investigate the potential mechanism of FoxO3a-induced cell migration, changes in the expression of TGF- $\beta 1$ induced-EMT markers were examined in FoxO3a-upregulated $\mathrm{HaCaT}$ cells. The results of the immunofluorescence and western blot assays demonstrated that the expression of E-cadherin in HaCaT cells decreased substantially, and the expression of vimentin increased, compared with the control cells (Fig. 5A and B). These data proved that the upregulation of the transcription factor FoxO3a was able to suppress the EMT process of HaCaT cells.

In addition, the western blot analysis results further revealed that the expression of $\beta$-catenin, a key molecule of the Wnt pathway, was increased in the cytoplasm and nucleus once $\mathrm{HaCaT}$ cells were treated with FoxO3a siRNA (Fig. 5C). 

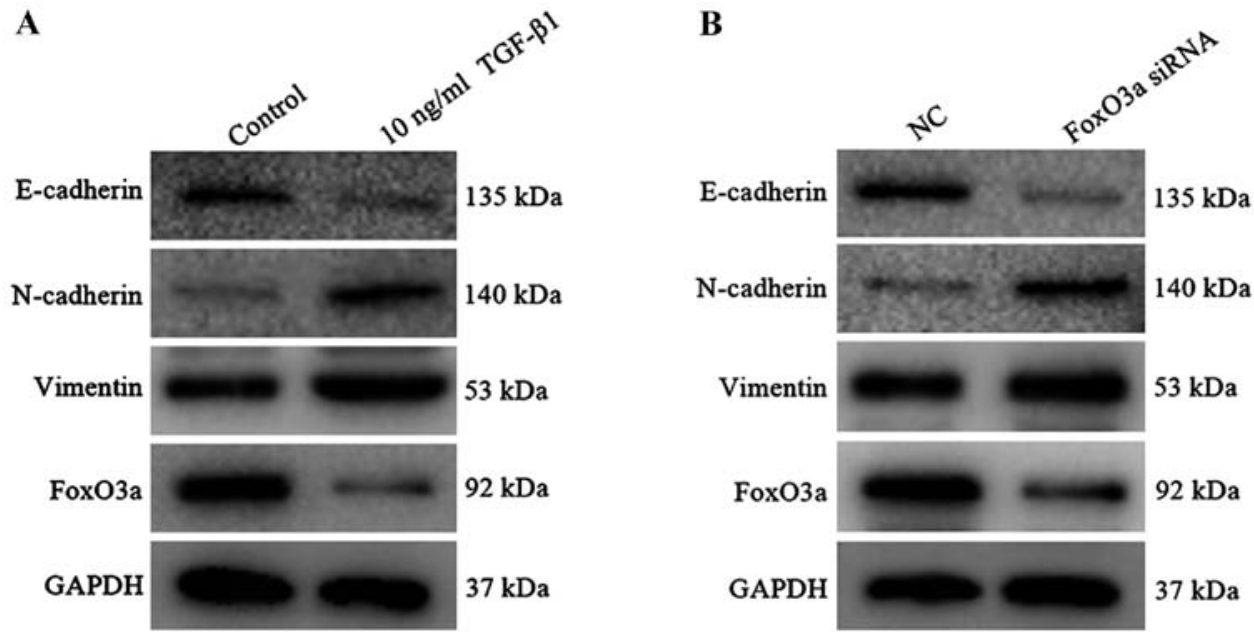

Figure 4. Construction of the epithelial-to-mesenchymal transition model in HaCaT cells. (A) Protein expression of N-cadherin, E-Cadherin, vimentin and FoxO3a were measured by western blot analysis subsequent to TGF- $\beta 1$ treatment. (B) Western blot analysis detected the change in N-cadherin, E-Cadherin, vimentin and FoxO3a expression once HaCaT cells were incubated with FoxO3a siRNA. FoxO3a, Forkhead box O3a; TGF- $\beta 1$, transforming growth factor- $\beta 1$; siRNA, small interfering RNA; NC, negative control.

A
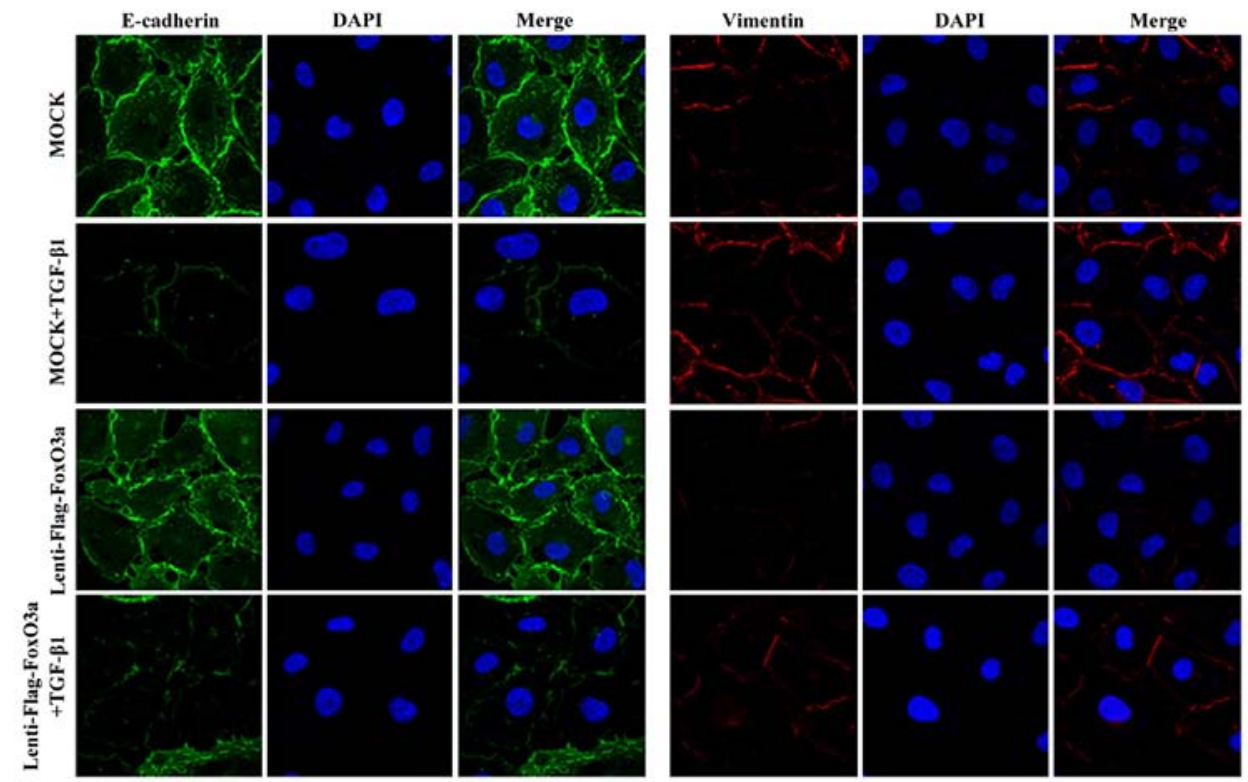

B

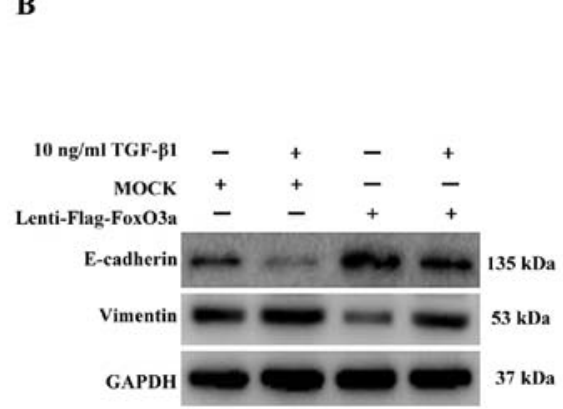

C
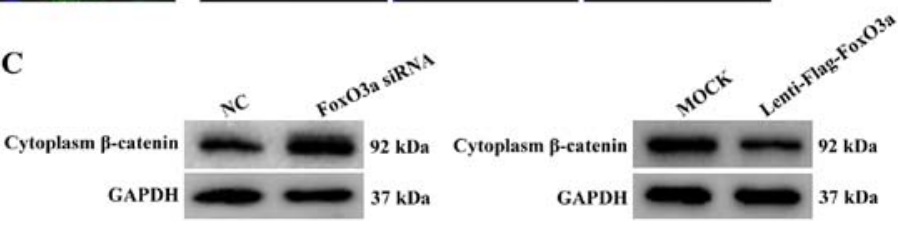

D

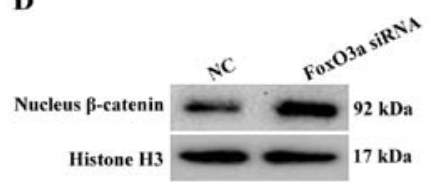

Figure 5. FoxO3a suppresses TGF- $\beta 1$-induced EMT and $\beta$-catenin expression. (A) Immunofluorescence (magnification, $\mathrm{x} 400$ ) and (B) western blot analysis were performed to detect the expression of TGF- $\beta 1$-induced EMT markers with FoxO3a overexpression. (C) Western blot analysis was performed to detect the cytoplasmic expression of $\beta$-catenin with either FoxO3a knockdown (left panel) or overexpression (right panel). (D) Western blot analysis was performed to verify the changes in $\beta$-catenin levels in the nucleus with either FoxO3a knockdown (left panel) or overexpression (right panel). The nuclei protein was normalized to Histone H3. EMT, epithelial-mesenchymal transition; FoxO3a, Forkhead box O3a; TGF- $\beta 1$, transforming growth factor- $\beta 1$; siRNA, small interfering RNA; NC, negative control.

By contrast, the expression of $\beta$-catenin in the cytoplasm and nucleus was substantially decreased once HaCaT cells were infected with lenti-flag-FoxO3a (Fig. 5D). Collectively, the present data demonstrated that the downregulation of FoxO3a 
accelerated the growth and migration of $\mathrm{HaCaT}$ cells in vitro, which notably affected the EMT process and increased the nuclear translocation of $\beta$-catenin.

\section{Discussion}

Re-epithelialization is an intricate, dynamic process that is dominated by $\mathrm{KC}$ cells and coordinated by multiple factors (25). The migration of KCs is regarded as a key speed-limiting step in the initiation of re-epithelialization, which is closely associated with the occurrence of chronic refractory wounds. Therefore, it is of great importance to identify the key regulatory factors that regulate the process of KC migration and initiate re-epithelialization for the rapid and effective healing of chronic refractory wounds. The data obtained in the present study revealed that FoxO3a is abundantly expressed in human chronic wound tissues compared with those in acute wound tissues. Further analyses revealed that silencing FoxO3a enhanced cell growth and caused a marked increase in the migration of $\mathrm{HaCaT}$ cells. Consistent with the expected results, the opposite result was observed in the FoxO3a overexpression group compared with the control. These results suggest that FoxO3a may negatively regulate the wound healing process.

MMPs are considered to be a crucial family of cell migration-associated proteins that degrade collagen and different components of the ECM, contributing to KC migration and the EMT during wound healing $(26,27)$. Previous studies have reported that the function of MMPs is regulated by numerous factors, including transcription factors, microRNAs and methylation modifications (28-30). Furthermore, further studies have demonstrated that the transcription factor FoxO3a is associated with the negative regulation of the MMP-1 and MMP-9 genes $(31,32)$. Therefore, the present study further observed that the inhibitory effect of FoxO3a upregulation on the migration of $\mathrm{HaCaT}$ cells was associated with reduced levels of MMP-1 and MMP-9, and increased the expression of TIMP-1. By contrast, the knockdown of FoxO3a substantially upregulated the expression of MMP-1 and MMP-9, and downregulated the expression of TIMP-1 compared with the control group. Altogether, these data suggest that FoxO3a contributes to $\mathrm{HaCaT}$ cell migration, partly by regulating the balance of MMP-1/TIMP-1 expression and controlling ECM degradation during wound healing.

Numerous reports have indicated that EMT is an essential condition for KC migration associated with wound healing $(24,33,34)$. Extensive previous studies have revealed that TGF- $\beta 1$ may induce the expression of migratory integrin in $\mathrm{KCs}$ to promote the gene transcription of downstream molecules, resulting in enhanced cellular proliferation and migration, and subsequently complete epithelialization (35-37). A previous clinical study has revealed that exogenous treatment with TGF- $\beta 1$ accelerated chronic wound healing, but it also may induce serious fibroblast effects, cause abnormal wound healing and form a pathological scar (38). The present study established an EMT model of $\mathrm{HaCaT}$ cells in vitro via TGF- $\beta 1$ stimulation. The results revealed that the expression of FoxO3a was decreased substantially during the process of EMT, suggesting that FoxO3a participated in the EMT of HaCaT cells, and its expression level was negatively associated with
EMT. Similarly, the depleted expression of FoxO3a promoted $\mathrm{N}$-cadherin and vimentin expression but decreased E-cadherin expression in $\mathrm{HaCaT}$ cells. In contrast with these results, the ectopic expression of FoxO3a blocked the TGF- $\beta 1$-induced EMT process. Thus, FoxO3a may function as a negative regulator of KC EMT, inhibiting cell migration and subsequently affecting the initiation of $\mathrm{KC}$ re-epithelialization.

$\beta$-catenin is a multifunctional protein involved in cell-to-cell adhesion, which activates the transcription transduction system by forming transcription factor complexes with lymphoid enhancer factor/T-cell factor (TCF) family members, thereby regulating cell growth and migration (39). Upon cutaneous injury, TGF- $\beta 1$ induces the accumulation of $\beta$-catenin in KC nuclei, and then functions downstream in the gene transcription of the Wnt pathway, causing EMT (40). Suppression of $\beta$-catenin expression may notably restrain the TGF- $\beta 1$-induced EMT process (41). In addition, a previous study reported that $\beta$-catenin serves a crucial function in the pathogenesis of chronic refractory skin ulcers, and its abnormal activity may be one of the reasons for the delayed healing of wounds (42). Furthermore, molecular evidence has revealed $\beta$-catenin as a master regulator of the FoxO3a-mediated suppression of EMT. FoxO3a inhibits $\beta$-catenin/TCF transcriptional activity via an indirect or direct interaction with $\beta$-catenin, thereby reducing the expression of $\beta$-catenin target genes, including MMPs $(15,43)$. Consistent with this result, the overexpression of cytoplasmic and nuclear $\beta$-catenin was observed during the silencing of FoxO3a-induced accelerated HaCaT migration in the present study, whereas restoration of FoxO3a levels induced the opposite effect, as the process of EMT was blocked and the expression of $\beta$-catenin decreased notably, suggesting that FoxO3a may negatively regulate the expression of $\beta$-catenin protein to control the process of EMT in $\mathrm{HaCaT}$ cells.

In conclusion, the present results demonstrated that the depletion of FoxO3a accelerates wound healing by promoting $\mathrm{KC}$ proliferation and migration during the process of re-epithelialization, and the mechanism appeared to involve the activation of EMT and $\beta$-catenin. These results provide a promising therapeutic approach for improving chronic wound healing.

\section{Acknowledgements}

Not applicable.

\section{Funding}

No funding was received.

\section{Availability of data and materials}

The datasets used and/or analyzed during the current study are available from the corresponding author on reasonable request.

\section{Authors' contributions}

DLF conceived and designed the experiments. TL, JZH and RSY conducted the experiments. TL and ZYL analyzed the data. RSY contributed the reagents/materials. TL wrote the 
manuscript. All authors read and approved the final version of the manuscript.

\section{Ethics approval and consent to participate}

The present study was ethically approved by The Research Ethics Committee of The Second Affiliated Xinqiao Hospital of Army Medical University (Chongquing, China) and written informed consent was obtained from each patient prior to surgery.

\section{Patient consent for publication}

Not applicable.

\section{Competing interests}

The authors declare that they have no competing interests.

\section{References}

1. Van Koppen CJ and Hartmann RW: Advances in the treatment of chronic wounds: A patent review. Expert Opin Ther Pat 25 931-937, 2015.

2. Sorg H, Tilkorn DJ, Hager S, Hauser J and Mirastschijski U: Skin wound healing: An update on the current knowledge and concepts. Eur Surg Res 58: 81-94, 2017.

3. Powers JG, Higham C, Broussard K and Phillips TJ: Wound healing and treating wounds: Chronic wound care and management. J Am Acad Dermatol 74: 607-626, 2016.

4. Pastar I, Stojadinovic O, Yin NC, Ramirez H, Nusbaum AG Sawaya A, Patel SB, Khalid L, Isseroff RR and Tomic-Canic M: Epithelialization in wound healing: A comprehensive review. Adv Wound Care (New Rochelle) 3: 445-464, 2014

5. Martin P and Nunan R: Cellular and molecular mechanisms of repair in acute and chronic wound healing. Br J Dermatol 173 370-378, 2015

6. Moura LI, Cruz MT and Carvalho E: The effect of neurotensin in human keratinocytes- implication on impaired wound healing in diabetes. Exp Biol Med (Maywood) 239: 6-12, 2014.

7. Xue $\mathrm{M}$ and Jackson CJ: Extracellular matrix reorganization during wound healing and Its impact on abnormal scarring. Adv Wound Care (New Rochelle) 4: 119-136, 2015.

8. Katoh M and Katoh M: Human FOX gene family (Review). Int J Oncol 25: 1495-1500, 2004

9. Kim CG, Lee H, Gupta N, Ramachandran S, Kaushik I, Srivastava S, Kim SH and Srivastava SK: Role of Forkhead Box Class $\mathrm{O}$ proteins in cancer progression and metastasis. Semin Cancer Biol 50: 142-151, 2018.

10. Gurkar AU, Robinson AR, Cui Y, Li X, Allani SK, Webster A, Muravia M, Fallahi M, Weissbach H, Robbins PD, et al: Dysregulation of DAF-16/FOXO3A-mediated stress responses accelerate oxidative DNA damage induced aging. Redox Biol 18 191-199, 2018

11. Liu Y, Ao X, Ding W, Ponnusamy M, Wu W, Hao X, Yu W, Wang Y, Li P and Wang J: Critical role of FOXO3a in carcinogenesis. Mol Cancer 17: 104, 2018.

12. Chaanine AH, Kohlbrenner E, Gamb SI, Guenzel AJ, Klaus K, Fayyaz AU, Nair KS, Hajjar RJ and Redfield MM: FOXO3a regulates BNIP3 and modulates mitochondrial calcium, dynamics, and function in cardiac stress. Am J Physiol Heart Circ Physiol 311: H1540-H1559, 2016.

13. Coomans de Brachène A and Demoulin JB: FOXO transcription factors in cancer development and therapy. Cell Mol Life Sci 73: $1159-1172,2016$

14. Taylor S, Lam M, Pararasa C, Brown JE, Carmichael AR and Griffiths HR: Evaluating the evidence for targeting FOXO3a in breast cancer: A systematic review. Cancer Cell Int 15: 1, 2015.

15. Liu H, Yin J, Wang H, Jiang G, Deng M, Zhang G, Bu X, Cai S, $\mathrm{Du} \mathrm{J}$ and $\mathrm{He} \mathrm{Z}$ : FOXO3a modulates WNT/ $\beta$-catenin signaling and suppresses epithelial-to-mesenchymal transition in prostate cancer cells. Cell Signal 27: 510-518, 2015.
16. Roupé KM, Nybo M, Sjöbring U, Alberius P, Schmidtchen A and Sørensen OE: Injury is a major inducer of epidermal innate immune responses during wound healing. J Invest Dermatol 130: $1167-1177,2010$.

17. Roupé KM, Veerla S, Olson J, Stone EL, Sørensen OE, Hedrick SM and Nizet V: Transcription factor binding site analysis identifies FOXO transcription factors as regulators of the cutaneous wound healing process. PLoS One 9: e89274, 2014

18. Livak KJ and Schmittgen TD: Analysis of relative gene expression data using real-time quantitative PCR and the 2(-delta delta C(T)) method. Methods 25: 402-408, 2001.

19. Li H, He B, Liu X, Li J, Liu Q, Dong W, Xu Z, Qian G, Zuo H, Hu C, et al: Regulation on toll-like receptor 4 and cell barrier function by Rab26 siRNA-loaded DNA nanovector in pulmonary microvascular endothelial cells. Theranostics 7 : 2537-2554, 2017.

20. Qi XF, Chen ZY, Xia JB, Zheng L, Zhao H, Pi LQ, Park KS, Kim SK, Lee KJ and Cai DQ: FoxO3a suppresses the senescence of cardiac microvascular endothelial cells by regulating the ROS-mediated cell cycle. J Mol Cell Cardiol 81: 114-126, 2015.

21. Tracy LE, Minasian RA and Caterson EJ: Extracellular matrix and dermal fibroblast function in the healing wound. Adv Wound Care (New Rochelle) 5: 119-136, 2016.

22. Ligi D, Mosti G, Croce L, Raffetto JD and Mannello F: Chronic venous disease-Part II: Proteolytic biomarkers in wound healing. Biochim Biophys Acta 1862: 1900-1908, 2016.

23. Seeger MA and Paller AS: The roles of growth factors in keratinocyte migration. Adv Wound Care (New Rochelle) 4: 213-224, 2015.

24. Stoll SW, Rittié L, Johnson JL and Elder JT: Heparin-binding EGF-like growth factor promotes epithelial-mesenchymal transition in human keratinocytes. J Invest Dermatol 132: 2148-2157, 2012.

25. Wu X, Yang L, Zheng Z, Li Z, Shi J, Li Y, Han S, Gao J, Tang C, $\mathrm{Su} \mathrm{L}$ and Hu D: Src promotes cutaneous wound healing by regulating MMP-2 through the ERK pathway. Int J Mol Med 37: 639-648, 2016

26. Schultz GS, Davidson JM, Kirsner RS, Bornstein P and Herman IM: Dynamic reciprocity in the wound microenvironment. Wound Repair Regen 19: 134-48, 2011.

27. Krishnaswamy VR, Mintz D and Sagi I: Matrix metalloproteinases: The sculptors of chronic cutaneous wounds. Biochim Biophys Acta Mol Cell Res 1864: 2220-2227, 2017.

28. Guarneri C, Bevelacqua V, Polesel J, Falzone L, Cannavò PS, Spandidos DA, Malaponte G and Libra M: NF- $\kappa$ B inhibition is associated with OPN/MMP-9 downregulation in cutaneous melanoma. Oncol Rep 37: 737-746, 2017.

29. Falzone L, Candido S, Salemi R, Basile MS, Scalisi A, McCubrey JA, Torino F, Signorelli SS, Montella M and Libra M: Computational identification of microRNAs associated to both epithelial to mesenchymal transition and NGAL/MMP-9 pathways in bladder cancer. Oncotarget 7: 72758-72766, 2016.

30. Falzone L, Salemi R, Travali S, Scalisi A, McCubrey JA, Candido $S$ and Libra M: MMP-9 overexpression is associated with intragenic hypermethylation of MMP9 gene in melanoma. Aging (Albany NY) 8: 933-44, 2016.

31. Miao C, Li Y and Zhang X: The functions of FoxO transcription factors in epithelial wound healing. Australas J Dermatol 60: 105-109, 2019.

32. Kikuno N, Shiina H, Urakami S, Kawamoto K, Hirata H, Tanaka Y, Place RF, Pookot D, Majid S, Igawa M, Dahiya R and Dahiya R: Knockdown of astrocyte-elevated gene-1 inhibits prostate cancer progression through upregulation of FOXO3a activity. Oncogene 26: 7644-7655, 2007.

33. Haensel D and Dai X: Epithelial-to-mesenchymal transition in cutaneous wound healing: Where we are and where we are heading. Dev Dyn 247: 473-480, 2018.

34. Stone RC, Pastar I, Ojeh N, Chen V, Liu S, Garzon KI and Tomic-Canic M: Epithelial-mesenchymal transition in tissue repair and fibrosis. Cell Tissue Res 365: 495-506, 2016.

35. Kim HY, Jackson TR and Davidson LA: On the role of mechanics in driving mesenchymal-to-epithelial transitions. Semin Cell Dev Biol 67: 113-122, 2017.

36. Tsubakihara Y and Moustakas A: Epithelial-mesenchymal transition and metastasis under the control of transforming growth factor $\beta$. Int J Mol Sci 19: E3672, 2018.

37. Ramirez H, Patel SB and Pastar I: The role of TGF $\beta$ signaling in wound epithelialization. Adv Wound Care (New Rochelle) 3: 482-491, 2014. 
38. Philandrianos C, Kerfant N, Jaloux C Jr, Martinet L, Bertrand B and Casanova D: Keloid scars (part I): Clinical presentation, epidemiology, histology and pathogenesis. Ann Chir Plast Esthet 61: 128-135, 2016 (In French).

39. Kumar R and Bashyam MD: Multiple oncogenic roles of nuclear beta-catenin. J Biosci 42: 695-707, 2017.

40. Bielefeld KA, Amini-Nik S and Alman BA: Cutaneous wound healing: Recruiting developmental pathways for regeneration. Cell Mol Life Sci 70: 2059-2081, 2013.

41. Gao F, Alwhaibi A, Sabbineni H, Verma A, Eldahshan W and Somanath PR: Suppression of Akt1- $\beta$-catenin pathway in advanced prostate cancer promotes TGF $\beta 1$-mediated epithelial to mesenchymal transition and metastasis. Cancer Lett 402: 177-189, 2017.
42. Zhang H, Nie X, Shi X, Zhao J, Chen Y, Yao Q, Sun C and Yang J: Regulatory mechanisms of the Wnt/ $\beta$-catenin pathway in diabetic cutaneous ulcers. Front Pharmacol 9: 1114, 2018.

43. Nawrocki-Raby B, Gilles C, Polette M, Martinella-Catusse C, Bonnet N, Puchelle E, Foidart JM, Van Roy F and Birembaut P: E-Cadherin mediates MMP down-regulation in highly invasive bronchial tumor cells. Am J Pathol 163: 653-561, 2003.

cc)(ㅇ) This work is licensed under a Creative Commons c) Attribution-NonCommercial-NoDerivatives 4.0 International (CC BY-NC-ND 4.0) License. 